\title{
Learning from Sociability-Intensive Organizations: An Ethnographic Study in a Coffee Organization
}

Letícia Fantinel $^{1}$

Eduardo Paes Barreto Davel ${ }^{2}$

${ }^{1}$ Universidade Federal do Espírito Santo, Vitória, ES, Brazil

${ }^{2}$ Universidade Federal da Bahia, Salvador, BA, Brazil

Received 28 November 2018. This paper was with the authors for two revisions. Accepted 19 December 2019. First published online $2^{\text {nd }}$ March 2020.

Josiane Oliveira was the associate editor for this article.

Editorial assistant: Luciane Kato Kiwara

Editor-in-chief: Carlo Gabriel Porto Bellini 


\begin{abstract}
Sociability is quintessential to some types of organizations, such as cafes, clubs, sports associations, gyms, bars, nightclubs, and festivals. If sociability is broadly theorized and discussed in the Social Sciences, it is indirectly, fragmentally, and diffusely considered in Organization Studies. Our study aims to theorize on the centrality of sociability within organizations by developing the concept of sociability-intensive organization and by discussing its effects in terms of organizing and organizational space. We have produced three main conceptual axis: relation, experiences of space, and ambience. Based on an ethnographic study, sociability-intensive organizations are conceptualized from three organizing processes: the fabrication of spontaneity, the fluidity of spatiality, and the fertilization of dialogue. These processes emerge from the ethnographic interpretation and contribute to theorize sociability as a paramount key for understanding organizations.
\end{abstract}

Keywords: sociability-intensive organizations; sociability; ethnography; organizational space; coffee organization. 


\section{Introduction}

In the context of the growth of individualism (Bauman, 2001a) and the development of cities and urban cultures (Zukin, 1995), people are constantly searching for different types of places and collectivities (see, e.g., Bauman, 2001b) as alternative spaces for meeting and socializing (Frugoli, 2007) on a regular basis. Many of these places are organizations that rely on the work of managers. More and more, contemporary life is deeply embedded in organizations that provide sociability as a good. While we perceive sociability as strategic for contemporary organizations, and while we have consolidated knowledge about it in the Social Sciences, we lack structured knowledge in Organization Studies on sociability as a central ingredient of organizational processes. Organizational scholars have considered social relations as an inherent and diffused concept of organizational analysis and theorization. Even though sociability has been considered a spontaneous process of organizational life, this notion has not yet been proposed as a central, robust, and strategic concept in organizational theory.

The main goal of the present research is to theorize on the centrality of sociability within organizations by developing the concept of sociability-intensive organization and by identifying its effects in terms of the production of organizational space and the process of organizing in a broader way. We understand the concept of organizing according to the theorization developed by Karl Weick, as a heuristic path to do both, highlight the processual dimensions of organizations and challenge the static notion of organization as a fixed and rigid entity (Czarniawska, 2008; Duarte \& Alcadipani, 2016; Weick, Sutcliffe, \& Obstfeld, 2005).

Sociability-intensive organization is elaborated as a key concept, in which sociability is one of the most strategic goods produced by employees and offered to customers. Furthermore, sociabilityintensive organizations are formed by spaces that mediate the daily sociability modes engendered among urban dwellers. Sociability-intensive organizations highlight how sociability drives organization dynamics. They help every organization to rethink how the strategy role of sociability is being considered within organizational life and space. Indeed, all organizations are pervaded by sociability experiences that shape organizational spaces, although they may vary in their different levels of manifestation. Because sociability is intrinsic to the human condition, organizations cannot exist without a minimum level of sociability.

The origin of the concept of sociability lies in theories developed by Simmel (2003) and several studies from the Chicago School of Sociology. Thus, our theoretical framework is composed by an articulation of theories from Sociology and Organizational Studies. From that theoretical articulation, we consider sociability as a strategic dimension of organizational life. Furthermore, sociability provides us with a singular lens for grasping organizational dynamics, thereby enabling a better understanding of the daily, spatial, and cultural life of organizations. The connection between some types of organizations and sociability is manifestly intense. We develop the concept of sociability-intensive organization from an empirical study of a coffee organization, because the rise of coffee shops in the world is consistent with the growing notion of a public sphere in a new social context in which society is mediated by consumption (Cowan, 2008). Coffee shops around the world have, for decades, implied spaces of cosmopolitism and social interaction, from the

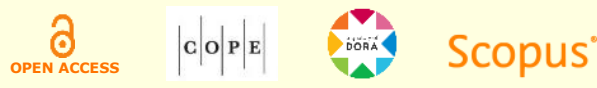


first establishments in Europe to contemporary global chains like Starbucks. In this sense, perhaps just like the taxi (Toiskallio, 2000), the coffee shop symbolizes any great multicultural city and requires singular organizational dynamics. The so-called cafe culture is part of the everyday life of cities, mediating social interaction in a playful sense (Bookman, 2014), in third places (Oldenburg, 1989) between public and private space.

The concept of sociability-intensive organization is based on empirical ground. Coffee organizations are emblematic to the study of sociability. As coffee shops increasingly appeared in Brazil, the act of going to these spaces came to be perceived as a new social, cultural, and economic fashion (Fantinel, Cavedon, \& Fischer, 2012), following the development of big cities, powered by the growth of the middle class (Souza \& Lamounier, 2010). Thus, we have conducted an ethnographic research in a coffee shop in Brazil. The ethnographic method allowed a better interaction with subtle and meaningful information on sociability, as we were able to have access to rich and context-sensitive information, as well as to conduct a deep interpretation of sociability in the organizational setting. Deep description and interpretation of how sociability is central in a coffee organization allow us to better understand the subtleties of sociability within organizations. They also allow the conception development of some processes that characterize sociability-intensive organizations: fabrication of spontaneity, fluidity of spatiality, and fertilization of dialogue.

The main contribution of our research is addressed to the field of Organization Studies, as we conceptualize, describe, and discuss the sociability-intensive organization as a strategic concept. We fill a theoretical gap that corresponds to the lack of knowledge about the concept of sociability and its centrality in terms of Organization Theory. Indeed, in Organization Studies, sociability is commonly taken for granted and assumed as a natural, intrinsic, and spontaneous phenomenon in organizational settings. Consequently, our research produces new conceptual categories that give centrality to the concept of sociability in Organization Studies. Moreover, it establishes new connections to organizing processes and organizational space. We assume that our perception and experience of space animate organization space (Taylor \& Spicer, 2007). Thus, space goes further than a matter of physical setting. Focusing on sociability-intensive organizations, we may enlarge our understanding of organizational space.

\section{Sociability in Organization Studies}

The concept of sociability was originally created by Simmel (2003), who perceived society as being continuously formed and dissolved by individuals through reciprocal interactions. Simmel (2003) conceived society as a way of organizing human experiences by designating a network of human relationships that occur in a particular time and space. From this perspective, sociability furthers the understanding of how society is organized because it is a type of interaction in which the interest and the goal are interaction itself.

The Chicago School of Sociology adopts an empirical approach to study and theorize about sociability (Graphmeyer \& Joseph, 2009). From a symbolic interactionist approach, Urban Studies and Sociology incorporate ethnographic practice into the study of sociability and consider

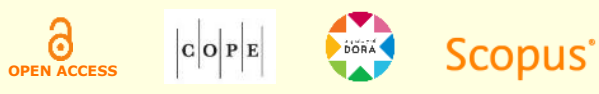


it as a tie to social life in cities (Zukin, 1995). Contemporaneously, some studies have adopted an interpretation of sociability based on a closer and broader view of everyday life in which different subjects and contexts are analyzed, beyond urban elites (Cowan, 2012). The notion of sociability has evolved from this traditional concept and has become a pivotal notion for analyzing social cohesion and distinction, communication, and relatedness to material cultures (Cowan, 2012). We see this movement as an effort towards the embodied and embedded dimensions of the sociability, which brings us closer to a processual and performative notion of space (Beyes \& Steyaert, 2011).

In Organizational Studies, the concept of sociability appears peripherally; it is fragmentally and vaguely discussed by organizational scholars. Research on organizational psychology and behavior understands sociability as the ability or the propensity to be sociable, as part of the larger phenomenon of organizational behavior (Nord \& Fox, 1996). Other researchers consider sociability as a dimension of organizational cultures, as the degree of friendliness among members of an organization (Goffee \& Jones, 1996).

Indeed, sociability can be considered from plural angles and understandings. In order to integrate the plural understandings, we propose organizational sociability, which is more contextual and enables a more specific and, at the same time, multidimensional analysis of organizational practice. This notion works as the interplay among individuals, mediating social interaction in an organization. It takes place inside and outside organizations; it occurs through symbolic and material processes, depending on the existence of three basic dimensions (relation among people, proper spatial context, and favorable ambience). As it acknowledges the valuable elements of organizational analysis, the concept of organizational sociability can enlarge the focus of the researcher and thereby encourage theoretical enrichment. From this viewpoint, we can conceptualize everyday organizational life as a dynamic field of sociability through which space is constantly experienced and reshaped. Sociability materializes through interactions in which social relations are reproduced and transformed (Llewellyn \& Hindmarsh, 2013). Interaction is a domain in which social relations reproduce and become practice through speech and attitude (Llewellyn \& Hindmarsh, 2013). Accordingly, expressions of social relations are visible elements of organizational sociability, depending on the context and culture of the organization. Interaction and relation are key ingredients in the analysis of sociability. Relation implies connection and association, while interaction occurs in a distinct dimension from formal, planned events. Indeed, not only employees but also customers, guests, and others socialize (Rollag, 2012).

Our understanding of organizational sociability is even more significant when we think of sociability-intensive organizations, whose core business is sociability in its full and multiple expressions. In these types of organizations, the main service offered is the interaction itself, what we call the business of sociability. A person can have a beer in many situations and spaces but instead she or he prefers to go to a bar. This is the understanding of a sociability-intensive organization: places where people go to socialize, interact, and, eventually, buy something. In these organizations, sociability is strategic, especially when the organization achieves a competitive advantage by helping customers become connected, informed, and satisfied (Rollag, 2012).

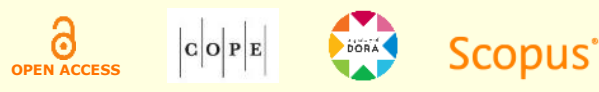


Space itself, embedded and symbolic, is a crucial element because the material world can shape relationships, even though social space may sometimes be perceived as natural and unquestionable (Dale \& Burrell, 2008). Organizations physically shape and reshape the workplace to better achieve institutional objectives and to encourage individuals to identify the organization with specific meanings (Dale \& Burrell, 2008). Nevertheless, individuals always find a space for subversion (Munro \& Jordan, 2013). The phenomenon occurs in both ways: spaces and places construct us as we construct them (Dale \& Burrell, 2008).

Organizational sociability is about the collective production of everyday life in organizations (Fantinel, 2016). It is a type of social interaction performed in order to produce certain ambience in organizational spaces. Several surveys call for a processual and dynamic understanding of organizational space (Beyes \& Steyaert, 2011; Domingues, Fantinel, \& Figueiredo, 2019; Munro $\&$ Jordan, 2013), highlighting the need to better know how spaces are created, appropriated, and transformed by individuals and groups.

From this theoretical framework, we could extract three main axis, seeking to describe the process of space production through sociability and having in mind the notion of space as lived experience (Taylor \& Spicer, 2007). Attached to this notion we agree that "different experiences of space give rise to radically different spaces" (Taylor \& Spicer, 2007, p. 333). According to this idea, we established the following axis: relation, inspired by the original notion of sociability, centered on the interactions among people (what happens among people in the space); experiences of space, focusing on how people live and appropriate it daily (how they experience the space); and, finally, ambience, showing the symbolic dimension produced by those experiences (what kind of space is produced from the mentioned experiences). These three axis guided our analysis procedures.

\section{The Business of Sociability: An Ethnographic Study in a Coffee Organization}

\section{Research methodology}

In order to explore the subtleties of organizational sociability, we conducted ethnographic research in a sociability-intensive organization: a coffee organization, located in Salvador, Bahia (in northeastern Brazil and its first capital in the past). In the city, coffee shops have gained great success and have become organizationally, culturally, and economically significant (Fantinel et al., 2012). The choice of this particular coffee shop in the city was mostly due to accessibility, as the owner was interested in the research, granting one of us (Anna) total access to the place.

The study involved six months of fieldwork and required full involvement in the coffee organization. Anna participated in the everyday tasks of the organization by preparing products, washing dishes, cleaning the space, eating with the employees, attending meetings, engaging with customers, and living the day-to-day life of the organization. 
Anna made 42 observations and spent 210 hours in the field, which resulted in an average of five hours of observation for each field visit. She carried a notepad and took notes when possible. Sometimes, due to the heavy routine, she made field notes when going back home. Then, at home, she rewrote the notes in a diary format.

Complementarily to the observation techniques, Anna conducted in-depth interviews with all the employees and the owner of the organization. In addition, four regular customers were also interviewed. The customers were selected based on how long they had been attending the coffee organization and according to their willingness to discuss the organization, their interaction with others in the space, etc. They were interviewed in the coffee organization, during free time or after work.

Three different scripts were prepared based on the observations made during the fieldwork and on the three key notions extracted from the literature. The first script, for the employees, contained open questions about relations with colleagues, customers, and other people in the coffee organization (How would you describe the interaction with...?), about wider perceptions related to the space (i.e., What do you think about the setting of the organization?), and about differences from other organizations and coffee shops. In the script for the owner, we asked about the past and present of the coffee organization, about possibilities and challenges in terms of management, and also about the space and ambience created and developed. Finally, in the script for the customers, we asked about the features that led them to the place, about their interactions with employees, the owner, and other customers, and about their feelings regarding the space. Anna conducted the interviews and conversations in Portuguese and then translated them into the manuscript, always trying to be faithful to the original meaning of the statements.

We interacted with the data from the observations and interviews, guided by the theoretical reference and the evidence of the empirical work, always seeking to answer the following question: How sociability shapes space? Each diary and transcription was read and coded regarding situations of sociability that provided evidence of the three theoretical dimensions of interest: relation among people, proper spatial context, and favorable ambience. From these three dimensions, we extracted the following analytical axis: relation, experience, and ambience. Based on these, we organized the data into categories in accordance with the purposes previously established in the study. The relation axis was based on the subjects involved in processes of organizational sociability in the coffee organization. The experience axis led us to the ways in which different people live the space. Finally, in the ambience axis we explore the dynamics that produces the symbolic dimension of the space. This process is presented in Table 1 . 
Table 1

Dimensions, analytical axis, and categories

\begin{tabular}{lll}
\hline Dimension & Analytical axis & Category \\
\hline Relation among people & \multirow{2}{*}{ Relation } & Relations among employees \\
& & Relations between employees and customers \\
& Relations among customers \\
\hline Proper spatial context & Experience & Space for relationships and conflicts \\
& & Space for people to pass through and to stay in \\
$\begin{array}{l}\text { Symbolic production of a } \\
\text { favorable ambience }\end{array}$ & Ambience & Space of social distinction and status \\
\hline
\end{tabular}

\section{The E\&E coffee shop and people}

The Espresso \& Expression coffee organization (E\&E) employed one manager and six baristas who also served as attendants. The owner created the coffee organization with the objective of being a cultural space for middle and upper class patrons. The ambience was created in order to be a place of distinctive consumption, which was reflected in the products being more expensive than the average in the city. Open from 9 a.m. to 9 p.m., Monday to Saturday, E\&E served coffee, drinks, snacks, etc. Its physical space was quite small $\left(9 \mathrm{~m}^{2}\right)$, divided between an indoor and an outdoor area comprising two counters and a small mezzanine. E\&E had eight tables with chairs, one sofa and two armchairs. It also had a small library.

Most of the customers were people who lived and worked in the neighborhood. Noon until 2 p.m. and between 5 and 7 p.m. were the periods when the coffee shop experienced the greatest flow of clients. During the rest of the day, fewer customers were present, which allowed the employees to talk more freely to each other and to customers and other visitors.

The fieldwork started soon after the owner's agreement, with a formal but friendly presentation made to the employees. The baristas were curious and excited about the research and the ethnographer. At times, it was difficult to define who was observing or interviewing who. In the first weeks of the fieldwork, Anna alternated between internal and external spaces. Gradually, Anna started friendly conversations with the customers and employees, who, within a few days, accepted her in the field. At one point, the baristas interrupted Anna in front of new customers when she was introducing herself as a researcher: she should be known as the newest employee of the coffee organization.

Given Anna's presence inside the coffee organization (employees' area), the baristas started suggesting some backstage activities, i.e., cleaning, for her. They decided that she should begin with the sink (washing dishes), and gradually she was allowed to engage in food preparation and

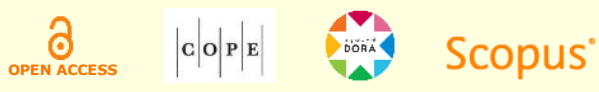


extraction of the espresso, a very noble activity for a barista. This path was part of the trajectory of new members of the company, which typically started with internal activities, and we interpreted it as part of the legitimization process for the researcher in the field.

\section{Relations for sociability: employees and customers}

E\&E was a meeting point for people. We observed people representing different social groups in the organization, and nearly every person mentioned friendliness and conviviality as being fundamental factors in the space. Workers from other places who were on their breaks visited the coffee shop organization, sometimes without consuming any products. At the tables, there were several topics of conversation, among which family issues, personal trajectories, and plans for the future were the most common.

In fact, the employees spent a considerable amount of time talking to each other. The lack of customers during the day often resulted in free time for the baristas, and it was during this time that we could observe many conversations. Indeed, the lack of separation between distraction and work is an aspect of the local culture. For example, in the diary, one of us says: "When I arrived, [one of the baristas] was talking to other two about soccer games. Only one of them was wearing the uniform, the others had just arrived. Both of them would start working within an hour. They could be anywhere. Still, they were at the coffee shop. The place was empty, and then they were talking lively" (field diary).

Anna also observed personal connections among employees and with the owner. For example, most of the employees addressed each other using nicknames. Even the owner was referred to by her first name by most of the workers. Consequently, we noted that establishing a familiar environment facilitates the development of organizational sociability. The organization's image as a place to build social ties had great prominence in the interviews.

However, sociability is shown not only through playful interactions but also through conflict. Indeed, conflict was an important core theme extracted from the data. In E\&E, there were a number of latent conflicts within the organizational environment that were noticeable from the comments made by the employees. The conflicts were diverse and included criticisms of colleagues' actions and perceptions of injustices regarding the distribution of certain tasks and work hours. Such conflicts can be observed in some sections of the field diaries, such as when Anna noted that some weeks "the mood is so bad that any detail can be cause for conflict or disagreement." In another situation, one of the diaries said: "People would complete their tasks only when the owner was physically in the coffee organization, according to the barista. In other situations, they just kept talking to each other. She said the owner should hire two more people to work there, that the distribution of tasks was uneven, and because of that, she didn't want to work there anymore. She asked for my opinion, if I agreed that this could be a sign that the organization had problems, that management was bad. I pretended that the question was rhetoric and did not respond, letting her continue."

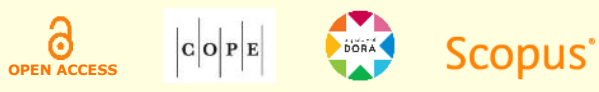


The two excerpts above show that the production of sociability not always is linked to friendly moments. Interests and disputes permeate organizational spaces and interfere in social interactions, as we can see in this part of the field diary: "[the barista] also told me about the fight she had with the owner. She said it was unfair what they have done to her. In her view, she was always available to change her schedule with the colleagues. This time, when she needed it, no colleague was there to take her place. Yesterday, when she had college tasks to do, the owner called her and said roughly that she had to cover the lack of other barista, even being on her day off."

During the research, we noticed regular and sporadic customers. Most customers of the coffee organization spent short periods of time there during their day, rarely exceeding one hour between arrival and departure. Among this group, we found employees from companies located in the neighborhood. Not all of the frequenters were actual customers, as some of them were employees from other places who were friends with the baristas. We perceived this as a conflict between two different perceptions: the customers wished to remain in the coffee shop without consuming, while the staff and managers wanted to increase consumption by the customers.

With regard to paying customers, the greatest number of customers went to the space immediately after lunch and, during this time, they appeared to be entertained with books, cell phones, or other gadgets. Because consumer attention was thus focused on a group of co-workers or on their watches and mobile phones, these customers did not interact with people outside of their immediate space/their table except when necessary. Even so, many of these customers could be considered habitués: those who frequent the area regularly enough to be recognized by employees or by other customers (Eleb \& Depaule, 2005).

There was another type of customer observed at the coffee organization, that is, people who had flexibility in their work schedules, such as artists, professors, freelancers, etc. These customers used the coffee organization to work. Not everyone, however, sought conversational interactions in the coffee organization. Some customers brought notebooks, tablets, and books with them and dedicated their time and attention to these objects. Sennett (1988) conceptualized this type of interaction, which involves simply seeing and being seen, as public isolation.

The need or desire to use the coffee organization as a place of refuge was expressed by the customers during interviews and informal conversations: "I want to escape the buzz of the mall," Anna recorded in the diaries. As we could see, commercial spaces can thus be considered as meeting places or sociability-intensive organizations. The sociability created in these commercial spaces responds to a contemporary perception of loneliness and isolation. Being in such a space goes beyond consumption and extends the possibility of meeting or making friends to develop sociability.

During the ethnographic activity, we were often unable to separate organizational sociability involving employees from organizational sociability involving customers. Conversations that began with employees frequently included the participation of customers. Additionally, 
customers often invited employees or Anna to participate in the dialogue. Such behaviors suggest that ambience is a trigger of interaction.

Commonly, we associate organizational sociability with the classic type of sociability reported by Simmel (2003), which in its purest form has no content or result outside itself. In this type of association, individuals construct their interactions in a superficial way so as not to expose details of their private lives (Graphmeyer \& Joseph, 2009). Under this form of sociability, we see people being both interested and indifferent.

However, even if the relations were ruled by some traces of superficiality, we could observe that they were very warm and friendly in general. As one of the baristas said: "A customer came here once and I thought she was kind of depressed. She looked sad. Then she ordered a caffè latte. I put two little dots [with milk] to make little eyes and a smile. She liked it so much that she seemed completely different afterwards. ... She came back another day and she said it had to be me [to prepare her latte] because I had made her smile again. ... Sometimes [coffee] is a way of communicating too."

This story illustrates how the barista, a professional who has to manage his or her appearance and expressions during work, can express through a product something that should not be said openly. It is a way to create a more welcoming ambience for customers and to communicate with them.

\section{Experience for sociability}

The employees and customers experienced the coffee organization as a pleasant place. The employees remained beyond their scheduled work hours in the space of the coffee organization. Activities were organized in shifts so that each employee had a different work schedule. They considered it acceptable to arrive at the coffee organization minutes or even hours before their scheduled shift. While waiting for their shift to begin, they sat at tables and chatted with colleagues and customers.

In the interviews, the customers talk about the space itself as being the primary reason for going to the coffee organization. E\&E was located in a quiet area that represented a refuge from the outside world. The space itself was perceived and defined as "cozy" and "comfortable." The organization was described as a quiet place, where people could escape from the chaos of everyday life. The comfort of the chairs, the ambient sound, and the proximity of the tables were all mentioned as being important factors that contributed to the overall feeling of comfort, thus creating a space that was highly conducive to sociability.

According to the customers, the space of the coffee shop evoked the feeling of being at home. In the words of one customer: "[to me the coffee shop means] a space for rest, and conversation. ... So I like it, especially because the place is quiet." This sense of familiarity was also observable

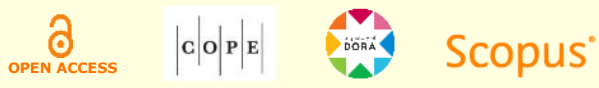


when customers received personal treatment from employees, often being addressed by their names, or when employees already knew their orders.

The sense of familiarity evokes what was described by some subjects as an artisanal space. E\&E had a symbolic nature related to its craft. These meanings were visible in actions reinforced by the owner (she claims to work with locally produced inputs; elements related to the craft are translated into the furniture and decoration), in the employees' activities (foods and drinks are handmade in slow processes), and also in the practices that appropriated the space (attention was given to customers; each service was seen as unique; people were relatively free to stay in the coffee organization and not consume anything). The construction of the business itself, with all these characteristics, reinforced these meanings (one of the clients even said that he "didn't feel in a commercial space"). Such practices of organization and management affect how people experience space, as we will explore further.

Finally, the experience of the space was reflected in what is called ambience, the final piece of the field data gathered during the study at E\&E; this is presented below.

\section{The ambience for sociability}

E\&E was established to generate a specific ambience. The notion of ambience refers to the character and atmosphere of a place, involving issues of feelings, impressions, and climate. The cozy space, the colors of the place, the comfortable armchairs, the yellow lights, and even its small physical dimensions all played a significant role in creating a feeling of comfort and well-being. The close tables facilitated direct contact among patrons.

The ambience of the space allowed spontaneous interaction among its frequenters. Anna participated in several conversations with employees and customers. Sometimes when the researcher was talking to someone, a customer at the next table would interject and join the conversation.

In terms of the ambience constructed in the space, it is relevant to mention that certain cultural aspects of Bahia can shape practices differently from other contexts. It reaffirms the contextual textures and expressions of sociability. In this regard, the predominance of the informal style of service is not only a feature of coffee shops but also of several local organizations. Informality and freedom in contact with others (in the diaries we can find descriptions of situations as baristas sitting with clients, clients offering little gifts to the baristas, the owner being called by nickname) are taken for granted in many organizations, which can cause some discomfort in clients from other regions of the country or other countries. We know migrants and tourists who reported this type of attitude as resulting from failure in training or a lack of professionalism when, in fact, it is a manifestation of local culture.

The ambience of E\&E was characteristic of a certain status and prestige associated with specific social groups. Being a customer of an organization such as E\&E can represent the adoption of social codes in society and, as such, this connection of meaning may transform a place into a lifestyle. This ambience is an example of the meanings associated with coffee shops in general as

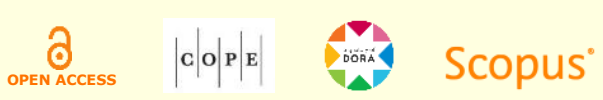


being spaces for intellectuals and artists. Contemporary coffee shops have maintained the roots of their existence with expectations of friendliness, spontaneity, and the centrality of conversation and interaction (Laurier, 2008).

Coffee organizations as well as other sociability-intensive organizations create space for exchanging ideas and interrupting routine activities, thereby enabling sociabilities that most likely would not exist outside of these places. They are spaces that open up a window to the city, offering an urban culture that is related to entertainment and leisure (Zukin, 1995) and representing small breaks in the routine of city inhabitants and workers.

\section{Sociability-intensive Organizations: Processes, Discussion, and Implications}

Several commercial spaces are frequently considered to be meeting places. Sociability can thereby become the core of the organization, and as such, it is the primary attraction for customers and demands the attention of managers. We can learn from organizations that strategically rely on sociability. The notion of sociability-intensive organizations gives centrality to the concept of sociability in the field of Organization Studies. It allows us to integrate theories from the Social Sciences in order to understand organizations as a meaningful and strategic space of sociability. As we think on sociability-intensive organizations as a key concept, we think about organizational sociability in a heuristic and strategic way. Organizational sociability may drive reflexive and strategic processes within organizations, as they connect clients, employees, and all types of stakeholders to the core of organizational activity or purpose.

During the interpretation of the ethnographic material, we identify three key dimensions associated with three organizing processes (Table 2) sustaining the way we can perceive sociabilityintensive organizations. These processes highlight the deep and extreme relationship that exists between sociability and organizations.

Table 2

Organizing processes sustaining sociability-intensive organizations

\begin{tabular}{lll}
\hline Dimensions & Analytical axis & Organizing processes \\
\hline Relation among people & Relation & Organizing the fertilization of dialogue and interaction \\
\hline Proper spatial context & Experience & Organizing the fluidity of space \\
\hline Symbolic production of a favorable ambience & Ambience & Organizing the fabrication of spontaneity \\
\hline
\end{tabular}

We present the aforementioned processes in detail in the next sections.

\section{Organizing the fertilization of dialogue and interaction}

Increasingly, consumption spaces have become places of social relationships. People seek spaces where they feel welcome and where they can relate with others, posing new challenges for managers. One of those challenges is what we call the fertilization of dialogue and interaction, that 
is, the promotion of practices that facilitate social interactions inside the organization. This idea gains even more importance when we consider sociability-intensive organizations.

The fertilization of dialogue represents the challenge of developing dialogue. However, it is not only through dialogue that sociability evolves. Indeed, our research shows that is important to think about the freedom needed to create relationships between customers and employees. We also highlight the importance of creating a friendly environment within the organization. Organization can foster customer loyalty by promoting dialogue.

The idea of fertilizing dialogue may serve as a step forward in the investigation of sociability in organizations. Focusing on three basic dimensions, we first emphasize the relation as a key mechanism that is visible from the moment we consider sociability to be a reciprocal action that occurs between at least two people and that materializes through a relational process. Thus, sociability takes form in the interaction itself, whether conversational or not, as it can occur not only through dialogue (Bohm, 1996) but also via other types of communication, such as nonverbal communication (Knapp \& Hall, 1997).

The sociability developed in the case studied between customers and employees most frequently occurred through conversation. Even in the cases of public isolation, some interaction was established. The fertilization of dialogue and interaction is exemplified by the conversations initiated by the customers themselves. We have demonstrated that the space can greatly aid these relations: it is one of the elements in this dynamic process.

Although interaction and dialogue are important aspects of this phenomenon, they offer nothing new to the theoretical field of sociability. The following two topics, however, present elements of this dynamic that have been ignored by the research: the fluidity of space and spontaneity.

\section{Organizing the fluidity of space}

Organizational sociability is a concept to be considered together with the space in which it occurs. In order to produce a certain ambience and to facilitate interaction, we must produce space, which is why we emphasize the organizational dimension of space. We argue that organizational sociability occurs both inside and outside the organizational space. Accordingly, we address the concept of sociability within an empirical approach, using modes, patterns, and forms of social relationships within contexts of social interactions (Frugoli, 2007). Once sociability takes place in relations, relations are perceived in their spatiotemporal frame.

We propose the assumptions that every organizational space is a social milieu (Chanlat, 2006) that cannot be isolated from the larger spatial context in which it occurs (Fleming \& Spicer, 2004) and that understanding organizational sociability through the space between the physical and the relational allows us to recognize the relationships, thus making the space itself the object of analysis. For this reason, we capture the space in its entirety, both relational and physical. 
Defining boundaries, forging what is public and what is private, what is work and what is leisure, corresponds to exercising power (Dale \& Burrell, 2008). We agree with this idea, but we also emphasize that there is always space to subvert these boundaries. On the one hand, organizations can physically reshape the workplace to better achieve institutional objectives and to encourage individuals to identify with the organization (Dale \& Burrell, 2008). On the other hand, clients and employees are constantly producing and reproducing new ways to live and conceive organizational spaces, as we can see in this research. This subversion of space operates in a social, interactive dimension, which is why the perspective of ambience is so relevant.

The ambience is critical for the occurrence of certain types of sociability. Consumers are attracted by the social dimensions of a business, as they perceive it as a personalized service. Accordingly, social and spatial dimensions reinforce each other. Meanings related to the space can produce and reproduce certain types of sociability, and organizations can physically shape the space to achieve institutional objectives (Dale \& Burrell, 2008). We go further, stating that these dimensions are important for understanding social and interactive practices in the space, but are also key factors for conceiving the organization's management.

For example, the fact that E\&E had an artisanal space made it more conducive to relationships because there was more freedom. We argue that organizations, in general, can learn from the artisanal production of space to become sociability-intensive. At E\&E, it was expressed in the care taken with the furniture, the colors of the walls, and the decorative objects that created a comfortable, cozy space. This artisanal production of symbolic space reinforces and is reinforced by practices and meanings that also refer to craft in day-to-day actions.

The peculiarities present in the space reinforce the pleasant ambience of the place, which favors the development of social relationships. In this sense, many precepts closely linked to the artisanal production and management of space are related to the ideas addressed in the next section. Artisanal spaces try to make people feel more comfortable and at ease by providing a pleasant and personalized ambience.

\section{Organizing the fabrication of spontaneity}

The third dimension is spontaneity, the key to integrating the other dimensions. The challenge we present herein is to create an environment conducive to sociability, which is accomplished by creating the means through which sociability is produced. Because ambience is formed from the development of relations in a space, we cannot underestimate the importance of creating a space conducive to interactions. This fluidity of space combined with freedom of interaction and the fertilization of dialogue is crucial to the development of sociability.

Unlike the first two dimensions presented herein, spontaneity is not addressed consistently in the literature, even though it is of great importance to understanding sociability at the organizational level. We argue that sociability is influenced by management, but these processes need a certain degree of freedom to occur. Thus, we assume that the types of social interaction

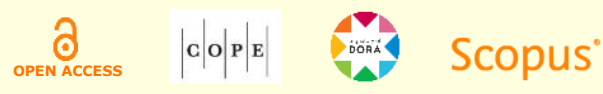


that we call sociability occur in certain ambiences in which people feel free to interact with others. It is this feeling of being at home, or feeling at ease, in some space that, when experienced by the components (customers or employees) of the organization, we refer to as spontaneity.

Spontaneity, the third dimension of sociability, is the product of the first two processes while simultaneously also producing them. Spontaneity calls people to experience sociability and a space that welcomes it, but at the same time, it transforms people and space. Accordingly, we have the origin of the phenomenon that we call sociability. However, it is misleading to think that spontaneity occurs randomly because it can, to some degree, be planned. As such, spontaneity is the product of elements and actions that contribute to the process of manufacturing spontaneity.

Theoretically, spontaneity is a phenomenon often related to improvisation and creativity, and accordingly, it constitutes an important dimension of analysis in fields such as the arts (Belgrad, 1998). Thus, freedom is a key word, as spontaneity favors unpremeditated and unconventional art (Belgrad, 1998). This view of spontaneity has been considered in Organization Studies with respect to what organizations can learn from the arts (Vera \& Crossan, 2004) and how organizations can implement improvisation (Kyriakopoulos, 2011). Spontaneity is also important in understanding the process of knowledge creation in organizations (Bourhis \& Dubé, 2010). Through these approaches, we aim to understand the creation of a certain ambience. Thus, our focus is not directed towards the development of organizational knowledge or the learning process but towards the creation of ambience for sociability.

Guerrier and Adib (2003) propose ways to address the fabrication of spontaneity by highlighting the importance of having freedom to interact with customers in certain organizations, such as bars and nightclubs. However, this freedom is relative, as the possibility for the employee to be himself or herself is restricted. Thus, while employees may be more or less authentic in this roleplaying, the role must meet the expectations of customers and organizations.

At E\&E, the spontaneity dimension refers to the artisanal ambience and management. They were responsible for providing employees with the freedom to relate to customers, thus increasing the sense of being at ease and being able to creatively develop their work, e.g., the professional barista has an artistic component, in a certain physical and symbolic space that is filled with fluidity.

The management-work-space triad is important in understanding how spontaneity can be created and sociability can be facilitated. Management is the key to providing conditions to establish ambience and to defining aspects such as the nature of the work and the space. While space is an underlying element in this context, it is no less important than the other elements because ambience is a complex combination of the physical space and the relations that take place there. The work is also relevant and how it is performed in the organization has a direct impact on the customers' perception and appropriation of the space. Furthermore, the perceptions of the employees on the job are important in defining their personal relationships within the work environment.

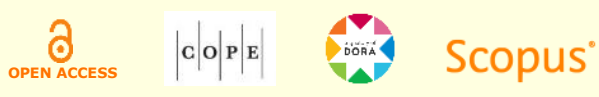




\section{Conclusion}

Sociability is quintessential for ongoing organizational existence, regardless of the type of organization. Therefore, understanding the dynamics of organizational sociability is crucial for any organization because it can provide us with more faithful understandings about the values related to cultures, practices, and strategies. This perspective encourages an unraveling of the ongoing practices, meanings, and representations driving organizational life. Accordingly, our aim was to theorize on the centrality of sociability within organizations by developing the concept of sociability-intensive organization and by identifying its effects in terms of the production of organizational space and the process of organizing in a broader way.

The main contribution of this research is to clarify a diffused and fragmented concept and bring it to the center of the Organization Studies debate. Sociability has been studied in the Social Sciences, but we were missing an integrated view in the field of Organization Studies. By developing the concept of sociability-intensive organizations, we hope to bring organizational sociability to the center of Organization Studies. Our research associated organizational sociability to the concepts of relation, experience, and ambience, as these facilitate the visualization of culture through sociability. Indeed, they help us to explain organizational routines such as coffee breaks and practices that go beyond the organizational space but are still related to it, such as happy hours. These situations and events are essential to understand organizations.

Sociability-intensive organizations displace organizational sociability from the place of secondary concept to a place of central one, presenting it as a multidimensional and strategic phenomenon to improve our understanding of contemporary organizations. This shift allows us to advance the theory and extend our conceptualization of spatial and social dimensions of organizational life. Focusing on organizational sociability extends our perspective of everyday life within the organization, unveiling its cultural and spatial manifestations throughout daily experiences. From an ethnographic research, we stressed the importance of integrating different processes and theories to make sense of organizational sociability and its influence on organizational space.

Due to the strong integration that includes organization, entertainment, and consumption, sociability-intensive organizations are becoming more and more central in our society. Increasingly often, we tend to seek pleasurable experiences when interacting with organizations, and thus developing these experiences involves understanding and managing issues related to sociability. However, in this regard, the main concern goes beyond a general understanding of organizations. Strategic dimensions within a dynamic, interactive, and ongoing perspective on organizational sociability include organizing the fertilization of dialogue and interaction, managing the fluidity of space, and managing the fabrication of spontaneity, because these are inevitable processes of sociability-intensive organizations. Consequently, these are inevitable processes for sustaining the business of sociability.

When we talk about organizational sociability, we may wonder about the role of managers within this phenomenon. Sociability-intensive organizations open a field of reflection about the managing processes of sociability within organizations and an agency dimension. Would

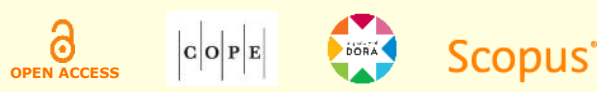


sociability be a management outcome? Can we manage sociability as an organizational resource or a singular type of capital? How can managers deal with organizational sociability? These issues provoke further research to explore the many links between sociability, management, and sociability-intensive organizations.

\section{References}

Bauman, Z. (2001b). Community. Cambridge, UK: Polity Press.

Bauman, Z. (2001a). The individualized society. Cambridge, UK: Polity Press.

Belgrad, D. (1998). The culture of spontaneity: Improvisation and the arts in postwar America. Chicago, IL: University of Chicago Press.

Beyes, T., \& Steyaert, C. (2011). Spacing organization: Non-representational theory and performing organizational space. Organization, 19(1), 45-61. https://doi.org/10.1177/1350508411401946

Bohm, D. (1996). On dialogue. London, UK: Routledge.

Bookman, S. (2014). Brands and urban life: Specialty coffee, consumers, and the co-creation of urban café sociality. Space and Culture, 17(1), 85-99. https://doi.org/10.1177/1206331213493853

Bourhis, A., \& Dubé, L. (2010). "Structuring spontaneity": Investigating the impact of management practices on the success of virtual communities of practice. Journal of Information Science, 36(2), 175-193. https://doi.org/10.1177/0165551509357861

Chanlat, J. F. (2006). Space, organization and management thinking: A socio-historical perspective. In S. Clegg, \& M. Kornberger (Eds.), Space, organizations and management theory (pp. 17-43). Ljubljana, Slovenia: Liber \& Copenhagen Business School Press.

Cowan, B. (2008). The social life of coffee: The emergence of the British coffeehouse. London, UK: Yale University Press.

Cowan, B. (2012). Public spaces, knowledge, and sociability. In F. Trentman (Ed.), The Oxford handbook of the history of consumption (pp. 251-266). Oxford, NY: Oxford University Press.

Czarniawska, B. (2008). A theory of organizing. Cheltenham, UK: Edward Elgar.

Dale, K., \& Burrell, G. (2008). The spaces of organisation $\mathcal{E}$ the organisation of space: Power, identity and materiality at work. Basingstoke, UK: Palgrave Macmillan.

Domingues, F. F., Fantinel, L. D., \& Figueiredo, M. D. de. (2019). Between the conceived and the lived, the practiced: The crossing of spaces at the Arts and Crafts Fair of Namorados Square in Vitória/ES, Brazil. Organizações $\mathcal{E}$ Sociedade, 26(88), 28-49. https://doi.org/10.1590/1984-9260882

Duarte, M. de F., \& Alcadipani, R. (2016). Contribuições do organizar (organizing) para os estudos organizacionais. Organizações $\mathcal{E}$ Sociedade, 23(76), 57-72. https://doi.org/10.1590/1984-9230763

Eleb, M., \& Depaule, J. (2005). Paris: Societé de cafés. Paris, France: Imprimeur Eds De L'.

Fantinel, L. (2016). As sociabilidades nas organizações: Da sociologia formal às interações cotidianas. Revista Interdisciplinar de Gestão Social, 5(2), 139-151. Retrieved from https://portalseer.ufba.br/index.php/rigs/article/view/12513/11741

Fantinel, L., Cavedon, N., \& Fischer, T. (2012). Produção de significações do espaço e sociabilidade em um café artesanal de Salvador. Revista Interdisciplinar de Gestão Social, 1(3), 51-74. http://dx.doi.org/10.9771/23172428rigs.v1i3.10053

Fleming, P., \& Spicer, A. (2004). "You can checkout anytime, but you can never leave": Spatial boundaries in a high commitment organization. Human Relations, 57(1), 75-94. https://doi.org/10.1177/0018726704042715

Frugoli, H., Jr. (2007). Sociabilidade urbana. Rio de Janeiro, Brazil: Zahar.

Goffee, R., \& Jones, G. (1996). What holds the modern company together? Harvard Business Review, 74, 134-148. Retrieved from https://hbr.org/1996/11/what-holds-the-modern-company-together

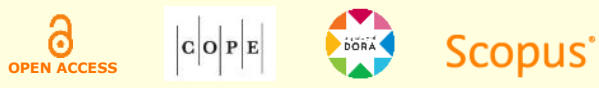


Graphmeyer, Y., \& Joseph, I. (2009). La ville laboratoire et le milieu urbain. In Y. Graphmeyer, \& I. Joseph (Eds.), L'école de Chicago: Naissance de l'écologie urbaine (pp. 5-52). Paris, France: Champs Essais.

Guerrier, Y., \& Addib, A. (2003). Work at leisure and leisure at work: A study of the emotional labour of tour reps. Human Relations, 56(11), 1399-1417. https://doi.org/10.1177/00187267035611006

Knapp, M., \& Hall, J. (1997). Nonverbal communication in human interaction. Fort Worth, TX: Harcourt Brace College Publishers.

Kyriakopoulos, K. (2011). Improvisation in product innovation: The contingent role of market information sources and memory types. Organization Studies, 32(8), 1051-1078. https://doi.org/10.1177/0170840611410833

Laurier, E. (2008). Drinking up endings: Conversational resources of the café. Language $\mathfrak{E}$ Communication, 28(2), 165-181. https://doi.org/10.1016/j.langcom.2008.01.011

Llewellyn, N., \& Hindmarsh, J. (2013). The order problem: Inference and interaction in interactive service work. Human Relations, 66(11), 1-26. https://doi.org/10.1177/0018726713479622

Munro, I., \& Jordan, S. (2013). "Living space" at the Edinburgh festival fringe: Spatial tactics and the politics of smooth space. Human Relations, 66(11), 1497-1525. https://doi.org/10.1177/0018726713480411

Nord, W., \& Fox, S. (1996). The individual in organizational studies: The great disappearing act? In S. Clegg, \& C. Hardy (Eds.), Studying organization: Theory $\mathcal{E}$ method (pp. 142-169). London, UK: Sage.

Oldenburg, R. (1989). The great good place: Cafés, coffee shops, community centers, beauty parlors, general stores, bars, hangouts, and how they get you through the day. New York, NY: Paragon House.

Rollag, K. (2012). Socializing the 'other' organizational newcomers - customers, clients, and guests. In C. Wanberg (Ed.), The Oxford handbook of organizational socialization (pp. 250-263). New York, NY: Oxford University Press.

Sennett, R. (1988). O declínio do homem público: As tiranias da intimidade. São Paulo, Brazil: Cia das Letras.

Simmel, G. (2003). The sociology of Georg Simmel (K. H. Wolff, Ed., Trans.). New York, NY: Free Press.

Souza, A., \& Lamounier, B. (2010). A classe média brasileira. Rio de Janeiro, Brazil: Elsevier.

Taylor, S., \& Spicer, A. (2007). Time for space: A narrative review of research on organizational spaces. International Journal of Management Reviews, 9(4), 325-346. https://doi.org/10.1111/j.1468-2370.2007.00214.x

Toiskallio, K. (2000). Simmel hails a cab: Fleeting sociability in the urban taxi. Space and Culture, 3(6), 4-20. https://doi.org/10.1177\%2F120633120000300214

Vera, D., \& Crossan, M. (2004). Theatrical improvisation: Lessons for organizations. Organization Studies, 25(5), $727-$ 749. https://doi.org/10.1177/0170840604042412

Weick, K. E., Sutcliffe, K. M., \& Obstfeld, D. (2005). Organizing and the process of sensemaking. Organization Science, 16(4), 409-421. https://doi.org/10.1287/orsc. 1050.0133

Zukin, S. (1995). The culture of cities. Oxford, UK: Blackwell Publishers.

\section{Author contributions}

$1^{\text {st }}$ author: conceptualization (equal), data curation (equal), formal analysis (equal), investigation (equal), methodology (equal), project administration (lead), writing-original draft (lead), writing-review and editing (equal). $2^{\text {nd }}$ author: conceptualization (equal), data curation (equal), formal analysis (equal), investigation (equal), methodology (equal), project administration (supporting), writing-original draft (supporting), writing-review and editing (equal). 


\section{Authors}

\section{Letícia Fantinel}

Universidade Federal do Espírito Santo, Departamento de Administração

Av. Fernando Ferrari, 514, 29060-700, Vitória, ES, Brazil

leticiafantinel@gmail.com

(iD) https://orcid.org/0000-0002-4589-6352

\section{Eduardo Paes Barreto Davel}

Universidade Federal da Bahia, Escola de Administração

Av. Reitor Miguel Calmon, 40110-060, Salvador, BA, Brazil

davel.eduardo@gmail.com

(iD) https://orcid.org/0000-0003-0610-6474

Peer review is responsible for acknowledging an article's potential contribution to the frontiers of scholarly knowledge on business or public administration. The authors are the ultimate responsible for the consistency of the theoretical references, the accurate report of empirical data, the personal perspectives, and the use of copyrighted material. 